\title{
Análise dos Principais Fluxos de Abastecimento de Biomassa Florestal em Portugal
}

\author{
Jorge Cunha1,2 e Alexandra Marques ${ }^{1,2}$
}

Sumário. A procura crescente de biomassa florestal para satisfazer um conjunto cada vez mais alargado de utilizações confere novos desafios quanto à sua utilização. Aspetos como o tipo de biomassa, como pode ser utilizada, os impactos com a sua exploração e consequentemente a sua disponibilidade, são questões cada vez mais relevantes. Metodologias que permitam contribuir para dar este tipo de respostas e assim, apoiar a definição e implementação dos regulamentos e estratégias a nível nacional e europeu, são fundamentais para o desenvolvimento sustentável no contexto da bioeconomia e da economia circular. O presente estudo pretende contribuir para o fomento da utilização da biomassa florestal em Portugal através da análise das fontes de biomassa florestal disponíveis e suas principais utilizações, consubstanciada numa análise de fluxos de materiais ao nível do país e das capacidades de processamento atualmente instaladas. A metodologia proposta assenta em cinco etapas: 1) estabilização e adoção de conceitos comuns; 2) análise de dados estatísticos e obtenção de estimativas de fluxos de biomassa; 3) representação dos fluxos através de um Diagrama de Sankey; 4) análise de cenários; 5) validação pelos stakeholders. Tem como principal objetivo tornar possível a comparação entre diferentes regiões ou países e de monitorizar os fluxos de biomassa florestal ao longo do tempo. Deste modo, a abordagem proposta pode ser útil para apoiar a tomada de decisões de investimento nas empresas e também apoiar o desenho das políticas públicas setoriais.

Palavras-chave: Diagrama de Sankey; análise de cenários; bioeconomia; economia circular

\footnotetext{
${ }^{1}$ ForestWISE - Laboratório Colaborativo para a Gestão Integrada da Floresta e do Fogo. VILA REAL.

${ }^{2}$ INESC TEC, PORTO.

E-mail:j.cunha@forestwise.pt
} 


\section{Analysis of the Main Sources of Forest Biomass Supply in Portugal}

Abstract. The growing demand for forest biomass to satisfy an ever-wider range of uses brings new challenges for its use. Aspects such as the type of biomass, how it can be used, the impacts with its exploitation and consequently its availability, are increasingly relevant issues today. Methodologies that can contribute to providing this kind of answers and thus support the definition and implementation of regulations and strategies at national and European level are fundamental to sustainable development in the context of the circular bioeconomy. This study aims to contribute to the promotion of the use of forest biomass in Portugal through the analysis of available forest biomass sources and their main uses, substantiated by an analysis of material flows at country level and the processing capacities currently installed. The proposed methodology is based on five steps: 1) stabilization and adoption of common concepts; 2) analysis of statistical data and obtaining estimates of biomass flows; 3) representation of flows through a Sankey Diagram; 4) scenario analysis; 5) validation by stakeholders. Its main goal is to make possible the comparison between different regions or countries, to achieve and to monitor forest biomass flows over time. The proposed methodological approach can help to support the companies' investment decisions as well as help to design public policies for this sector.

Key words: Sankey diagram; scenario analysis; bioeconomy; circular economy

\section{Analyse des Principales sources d'Approvisionnement en Biomasse Forestière au Portugal}

Résumé. La demande croissante de biomasse forestière pour satisfaire un éventail d'utilisations toujours plus large pose de nouveaux défis pour son utilisation. Des aspects tels que le type de biomasse, la manière dont elle peut être utilisée, les impacts de son exploitation et, par conséquent, sa disponibilité, sont des questions de plus en plus pertinentes aujourd'hui. Les méthodologies qui peuvent contribuer à fournir ce type de réponses et ainsi soutenir la définition et la mise en œuvre de réglementations et de stratégies au niveau national et européen, sont fondamentales pour le développement durable dans le contexte de la bioéconomie circulaire. Cette étude vise à contribuer à la promotion de l'utilisation de la biomasse forestière au Portugal par l'analyse des sources de biomasse forestière disponibles et de leurs principales utilisations, concrétisée par une analyse des flux de matériaux au niveau national et des capacités de traitement actuellement installées. La méthodologie proposée repose sur cinq étapes: 1) stabilisation et adoption de concepts communs; 2) analyse des données statistiques et obtention d'estimations des flux de biomasse; 3) représentation des flux par un diagramme de Sankey; 4) analyse de scénarios; 5) validation par les parties prenantes. Son principal objectif est de permettre la comparaison entre différentes régions ou pays et de suivre les flux de biomasse forestière dans le temps. Cette étude contribue donc à l'accroissement des connaissances et constitue un outil utile pour soutenir la prise de décision, dans les 
Fluxos de Abastecimento de Biomassa 9

entreprises, dans la conception de politiques et de stratégies ou dans la définition d'instruments d'incitation.

Mots-clés: Diagramme de Sankey; analyse de scenarios; bioéconomie; économie circulaire 


\section{Introdução}

O fomento da utilização da biomassa florestal é um tema fulcral nas políticas e estratégias energéticas e florestais, nacionais e europeias. $\mathrm{O}$ uso crescente de biomassa como uma fonte de energia no século XXI terá um impacto significativo no desenvolvimento rural, agrícola e florestal (FAO, 2006). De facto, a Estratégia da União Europeia para as Florestas e o Sector Florestal, a Estratégica Nacional para as Florestas (DIÁRIO DA REPÚBLICA, 2015), e mais recentemente em legislação nacional específica publicada após os incêndios de 2017, incentivam a uma maior utilização de biomassa florestal, incluindo sobrantes da exploração florestal e outros tipos de biomassa atualmente pouco utilizados como os resíduos lenhosos provenientes da gestão dos matos, desbastes e desramas. Desta forma pretende-se contribuir para a maior sustentabilidade económica da floresta portuguesa e para a prevenção de incêndios. Também a legislação energética nacional aponta para a necessidade de aumentar as fontes energéticas provenientes da floresta, agricultura e dos resíduos, a par de outras fontes de energia renovável, de forma a atingir as metas de $40 \%$ de produção de energia a partir de fontes renováveis, definida na Politica Energética em Portugal que é superior aos $27 \%$ da meta europeia (FERREIRA et al., 2017).

Ambas as dimensões - florestal e energética - estão também patentes nas políticas recentes relacionadas com a Economia Circular e a Bioeconomia, tais como a Estratégia de Inovação para um Crescimento Sustentável: Bioeconomia para a Europa (COMISSÃO EUROPEIA, 2012), Fechar o ciclo - plano de ação da UE para a economia circular (COMISSÃO EUROPEIA, 2015) e o Plano de Ação para a Economia Circular em Portugal (DIÁRIO DA REPÚBLICA, 2017a). No seu conjunto, as políticas apontam para o aumento da contribuição do setor florestal português (incluindo a biomassa), cuja atual contribuição para a bioeconomia se estima em 38,6 biliões de euros em 2014, de acordo com o relatório do European Forest Institute (ARANO et al., 2018).

A par destas forças motrizes externas, o subsector da biomassa está em transformação com vista à otimização dos seus processos para reforço da produção de bioenergia - em 2017, a madeira e outros biocombustíveis sólidos, bem como a componente renovável de outros resíduos, foram as fontes de energia renováveis mais importantes na UE- 28 , representando $42 \%$ da produção 
primária de energia renovável ${ }^{1}$. Por outro lado, pretende-se a diversificação das fontes de biomassa usadas, passando a incluir outros resíduos florestais, sobrantes industriais e material pós-consumo. Pretende-se ainda aumentar o portfolio de produtos obtidos a partir da biomassa, segundo o paradigma do uso em cascata da biomassa, gerando por isso maior valor acrescentado a partir desta matéria prima renovável e com origem numa gestão florestal sustentável verificada através dos sistemas de certificação. Neste sentido, o Plano Nacional para a Promoção das Biorrefinarias (DIÁRIO DA REPÚBLICA, 2017b), a par com outros instrumentos de política europeia, fomenta a transformação da lignina e celulose em biorrefinarias para obtenção de novos biomateriais, têxteis, bioquímicos e plásticos. Deste modo, pretende-se contribuir ainda para um maior investimento nas zonas rurais, com impacto que se estende para além do sector florestal, abarcando outros setores como o energético, construção, fabrico de têxteis, plásticos, fármacos e cosméticos (HETEMÄKI, 2014) e por isso, com grande potencial para originar novos negócios num contexto da bioeconomia (SILLANPÄÄ and NCIBI, 2017; VERKERK, MARTINEZ DE ARANO and PALAHÍ, 2018).

Um aspeto chave é o redesenho das cadeias de abastecimento da biomassa florestal, nomeadamente os processos de recolha, pré-processamento e transporte, com vista à redução dos custos logísticos e aumento da quantidade e diversidade de fontes de biomassa florestal efetivamente utilizadas.

Neste contexto, o presente estudo pretende contribuir para o fomento da utilização da biomassa florestal em Portugal através da análise das fontes de biomassa florestal disponíveis e suas principais utilizações, consubstanciada numa análise de fluxos de materiais ao nível do país e das capacidades de processamento atualmente instaladas. Esta análise permitirá prever as disponibilidades e consumos face a novos cenários de evolução do setor, tais como a instalação de biorrefinarias para obtenção de novos bioquímicos e biomateriais.

\section{Revisão bibliográfica}

Consistiu na pesquisa de publicações técnicas e científicas disponíveis no Portal Science Direct, bem como outros documentos normativos. Os critérios de pesquisa foram: 1) ("wood" OR "biomass") AND "material flow" NOT "life cycle"

${ }^{1}$ https:/ / ec.europa.eu/eurostat/statistics-explained/index.php?title=Renewable_energy_statistics/ pt\#Energias_renov.C3.A1veis_produzidas_na_UE_aumentaram_dois_ter.C3.A7os_em_2007-2017 
no título, sumário ou palavras-chave definidas pelo autor; 2) ano de publicação: desde 01/01/2010 a 01/12/2019; 3) Escrito em inglês. Pesquisaram-se ainda outros documentos técnicos e normativos escritos em Português, disponíveis através do Google Scholars, publicados desde 2000. A pesquisa foi efetuada entre junho de 2018 e setembro de 2019.

No total, acedeu-se a cerca de 500 documentos. A leitura do título e resumo permitiu selecionar 86, que foram analisados com mais detalhe, utilizando a técnica de Content Analysis (SHANNON, 2005). Separaram-se as publicações em 3 grupos: as referentes a análises de fluxos e capacidades, as referentes a processos logísticos e as gerais, enquadradoras às cadeias de abastecimento. No que diz respeito à análise dos fluxos e capacidades, a revisão da literatura permitiu sistematizar as categorias de biomassa florestal bem como as principais aplicações existentes em Portugal. A análise da literatura internacional, permitiu ainda identificar aplicações emergentes para a biomassa florestal. Os resultados detalhados da revisão da literatura estão publicados em Marques AF, Cunha J, DeMeyer A, Navare K. 2020. Contribution towards a comprehensive methodology for wood-based biomass material flow analysis in a circular economy setting. Forests 11 (1): 10.3390/f11010106 Special issue: "Supply Chain Optimization for Biomass and Biofuels" doi.org/10.3390/f11010106.

\section{Abordagem metodológica}

Com base na revisão bibliográfica, é proposto um esquema conceptual para a caracterização dos fluxos de biomassa florestal, que se pretende que seja adequado para utilização em Portugal e generalizável para outros países. Em relação a Portugal, para cada categoria de biomassa foram identificadas as fontes de dados atualmente existentes para a sua quantificação.

A Figura 1 representa, de forma esquemática, as etapas seguidas para a caracterização dos fluxos de abastecimento de biomassa florestal seguida neste estudo.

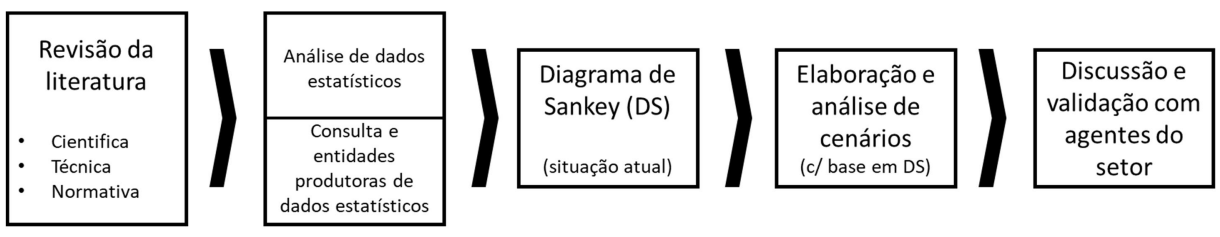

Figura 1 - Metodologia adotada neste estudo para a análise dos fluxos de produção e consumo de biomassa e capacidades de transformação 
1) Revisão bibliográfica: através da revisão bibliográfica, procurou-se definir conceitos até agora utilizados de forma distinta, com diferentes significados e utilizando diferentes unidades para a sua quantificação, dificultando a sua comparação.

2) Análise de dados estatísticos e obtenção de estimativas de fluxos de biomassa: Esta etapa consistiu na identificação das principais fontes de dados estatísticos para caracterização dos fluxos de biomassa florestal. $O$ ano de referência para este estudo é 2016. Foram analisados os principais repositórios de dados estatísticos nacionais, nomeadamente:

- Observatório para as fileiras florestais publicado pelo Instituto da Conservação da Natureza e das Florestas (ICNF, 2016);

- Estatísticas Agrícolas e Estatísticas Ambientais publicados pelo Instituto Nacional de Estatística (INE, 2018; INE, 2016);

- Dados disponibilizados pela Direção Geral de Energia e Geologia (DGEG).

Recorreu-se ainda a outras fontes estatísticas, nomeadamente as publicadas pela CELPA, pelo Centro Pinus e pela ANPEB.

Adicionalmente, foram consultadas as entidades produtoras de dados estatísticos através de entrevistas estruturadas com essas diferentes entidades de forma a colmatar falhas de informação existentes nos dados recolhidos e consultados, atualizar alguma da informação publicada e identificar informação disponível, mas não publicada. As entidades entrevistadas foram: ANPEB Associação Nacional de Produtores de Pellets, CBE - Centro de Biomassa para Energia, Centro Pinus - Associação para a Valorização da Floresta de Pinho, DGEG - Direção Geral de Energia e Geologia, ICNF -Instituto da Conservação da Natureza e das Florestas e UTAD - Universidade de Trás-os-Montes e Alto Douro.

Os dados recolhidos foram uniformizados, usando como unidade de referência a tonelada. Todas as conversões entre unidades foram efetuadas tendo em conta a Tabela de Conversão do (ex)Instituto dos Produtos Florestais, disponível no ICNF.

3) Representação dos fluxos através de um Diagrama de Sankey: a informação recolhida para a análise de fluxos e capacidades foi sistematizada sob a forma de um diagrama de fluxos de Sankey. Este tipo de diagrama é uma representação visual dos fluxos principais num sistema, entre locais de produção e locais de consumo e caracteriza-se por usar setas, representando fluxos, cuja espessura é proporcional à quantidade do fluxo. O recurso à representação dos fluxos por 
intermédio de diagramas de Sankey tem sido prática comum em diversas áreas (SCHMIDT, 2008) nomeadamente: na análise dos fluxos de energia (SOUNDARARAJAN, HO and SU, 2014); a dinâmica de alteração da ocupação do solo (CUBA, 2015); na análise de fluxos integrada com modelos económicos aplicado ao setor industrial francês de base florestal (LENGLET, COURTONNE and CAURLA, 2017); na caracterização dos fluxos de biomassa na Europa (CAMIA et al., 2018).

4) Elaboração e análise de cenários: Uma das potencialidades da metodologia proposta reside na possibilidade de se poderem definir cenários de evolução dos fluxos de abastecimento de biomassa florestal, por via de alterações nos volumes de biomassa florestal produzidos, nas capacidades de processamento e produção dos diferentes tipos de produtos derivados e de combinações que possam afetar a produção e/ou o consumo.

5) Discussão e validação dos resultados do estudo com os agentes do sector: o envolvimento dos stakeholders chave ao longo das diferentes fases do processo revela-se essencial para o reconhecimento e validação da metodologia proposta e como ponto de partida para a discussão dos resultados intermédios e finais, procurando assim que os mesmos sejam reconhecidos de forma consensual.

\section{Apresentação e discussão de resultados}

\section{1) Adoção de conceitos e terminologia comuns}

Uma preocupação deste estudo foi criar, desde logo, uma proposta de taxonomia para os conceitos fundamentais à análise dos fluxos de biomassa e também para clarificar os conceitos de biomassa florestal de forma a serem aplicados em Portugal e mapeáveis com as principais referências internacionais.

Assim, definem-se categorias de biomassa florestal de acordo com a sua proveniência, que se subdividem em subcategorias de acordo com as suas características físicas (Quadro 1):

i. Biomassa florestal primária (BFP): com origem na produção florestal primária, incluindo os resíduos lenhosos resultantes da instalação, gestão e exploração florestal

ii. Biomassa florestal secundária (BFS): com origem nos processos industriais de transformação de madeira, incluindo a serração, produção de painéis de madeira, pasta e papel, resíduos de cortiça e cascas de frutos secos. Nesta categoria está ainda incluída a pasta e 
papel recuperados e o material de origem lenhosa recuperado do pósconsumo doméstico e industrial, como por exemplo construções e demolições.

iii. Biomassa florestal primária (BFP): com origem na produção florestal primária, incluindo os resíduos lenhosos resultantes da instalação, gestão e exploração florestal

iv. Biomassa florestal secundária (BFS): com origem nos processos industriais de transformação de madeira, incluindo a serração, produção de painéis de madeira, pasta e papel, resíduos de cortiça e cascas de frutos secos. Nesta categoria está ainda incluída a pasta e papel recuperados e o material de origem lenhosa recuperado do pósconsumo doméstico e industrial, como por exemplo construções e demolições.

De notar, que, sempre que possível, estas categorias têm mapeamento direto com as designações utilizadas no inquérito Joint Forest Sector ${ }^{2}$ realizado a todos os estados membros da CE (em itálico e escrito em inglês).

Quadro 1 - Categorias e subcategorias de biomassa florestal usadas neste estudo

\begin{tabular}{|l|l|l|}
\hline Categoria & \multicolumn{1}{|c|}{ Subcategoria } & \multicolumn{1}{c|}{ Descrição } \\
\hline \multirow{2}{*}{$\begin{array}{l}\text { (BFP) } \\
\text { Biomassa } \\
\text { florestal } \\
\text { primária } \\
\text { wood in the } \\
\text { rough }\end{array}$} & $\begin{array}{l}\frac{1}{\text { madeira }} \text { roundwood } \\
\text { energéticas florestais } \\
\text { de espécies de rápido } \\
\text { crescimento } \\
\text { energy crops }\end{array}$ & $\begin{array}{l}\text { Toda a madeira cortada ou removida de outra forma. } \\
\text { Compreende toda a madeira obtida a partir de remoções, } \\
\text { ou seja, as quantidades removidas, incluindo a madeira } \\
\text { recuperada de perdas naturais ou não - fogo, vento, } \\
\text { insetos e doenças. Exclui a casca e outras biomassas não } \\
\text { lenhosas e qualquer madeira que não seja removida, por } \\
\text { exemplo cepos, ramos e restos de exploração. }\end{array}$ \\
\cline { 2 - 3 } & $\begin{array}{l}\text { Cultura florestal de rápido crescimento, cuja produção e } \\
\text { respetiva silvicultura preveja rotações inferiores a seis } \\
\text { anos e cuja transformação industrial seja dedicada à } \\
\text { produção de energia elétrica ou térmica (D.L. 64/2017). }\end{array}$ \\
\hline $\begin{array}{l}\text { (L) Lenha } \\
\text { wood fuel }\end{array}$ & $\begin{array}{l}\text { Material lenhoso para uso como combustível para } \\
\text { aquecimento doméstico e semi-industrial. Inclui madeira } \\
\text { proveniente do lenho, ramos e outras partes de árvores e } \\
\text { madeira utilizada para a produção de carvão vegetal. }\end{array}$ \\
\hline
\end{tabular}

${ }^{2}$ Joint Forest Sector Questionnaire Definitions (European Commission - DG Eurostat, FAO - Food and Agriculture Organization of the United Nations, ITTO - The International Tropical Timber Organization e UNECE - The United Nations Economic Commission for Europe). 
16 Cunha, J. e Marques, A.

Quadro 2 - Continuação

\begin{tabular}{|c|c|c|}
\hline Categoria & Subcategoria & Descrição \\
\hline \multirow{2}{*}{$\begin{array}{l}\text { (BFP) } \\
\text { Biomassa } \\
\text { florestal } \\
\text { primária } \\
\text { wood in the } \\
\text { rough }\end{array}$} & $\frac{\text { (MT) Matos e }}{\underline{\text { vegetação sobcoberto }}}$ & $\begin{array}{l}\text { Vegetação espontânea composta por mato (por ex.: urzes, } \\
\text { silvas, giestas, tojos) ou por formações arbustivas (ex.: } \\
\text { carrascais ou medronhais espontâneos). Vegetação que } \\
\text { cresce sob o copado do povoamento florestal. É } \\
\text { geralmente constituído por material vegetal do estrato } \\
\text { arbustivo ou herbácea, incluindo as pastagens sobcoberto } \\
\text { ou culturas agrícolas temporárias instaladas sob um } \\
\text { povoamento florestal. }\end{array}$ \\
\hline & $\begin{array}{l}\text { (RF) Resíduos } \\
\text { florestais ou resíduos } \\
\text { da exploração e } \\
\text { gestão florestal } \\
\text { (Forest residues) }\end{array}$ & $\begin{array}{l}\text { De acordo com D.L. } 64 / 2017 \text {, é a fração biodegradável } \\
\text { dos produtos e desperdícios resultantes da instalação, } \\
\text { gestão e exploração florestal (cepos, toiças, raízes, folhas, } \\
\text { ramos e bicadas), do material lenhoso resultante de } \\
\text { cortes fitossanitários, de medidas de defesa da floresta } \\
\text { contra os incêndios, e do controlo de áreas com invasoras } \\
\text { lenhosas. Neste estudo, as cascas das árvores estão } \\
\text { incluídas nesta categoria. }\end{array}$ \\
\hline \multirow{7}{*}{$\begin{array}{l}\text { (BFS) } \\
\text { Biomassa } \\
\text { florestal } \\
\text { secundária } \\
\text { (wood } \\
\text { chips, } \\
\text { particles, } \\
\text { and } \\
\text { residues) }\end{array}$} & $\begin{array}{l}\text { (SP1) Subprodutos } \\
\text { das indústrias de } 1^{\text {a }} \\
\text { transformação }\end{array}$ & $\begin{array}{l}\text { Subprodutos do processamento de madeira provenientes } \\
\text { das indústrias de serração, incluindo lascas de madeira, } \\
\text { aparas e outras partículas de madeira. }\end{array}$ \\
\hline & $\begin{array}{l}\text { (SP2) Subprodutos } \\
\text { das indústrias de } 2^{\text {a }} \\
\text { transformação }\end{array}$ & $\begin{array}{l}\text { Subprodutos das indústrias de painéis de madeira, } \\
\text { incluindo aglomerados de partículas, mas também } \\
\text { serrilha e cascas. }\end{array}$ \\
\hline & $\begin{array}{l}\text { (SP3) Subprodutos } \\
\text { das indústrias de } \\
\text { transformação } 3^{\text {a }}\end{array}$ & $\begin{array}{l}\text { Subprodutos da manufatura de produtos derivados de } \\
\text { madeira serrada e painéis de madeira na construção, } \\
\text { embalagens, móveis e outros, frequentemente incluindo } \\
\text { cortes de painéis à base de madeira, serragem, aparas. }\end{array}$ \\
\hline & $\begin{array}{l}\text { (SP4) Subprodutos } \\
\text { das indústrias de } \\
\text { pasta e papel }\end{array}$ & $\begin{array}{l}\text { Subprodutos do processamento de madeira provenientes } \\
\text { das indústrias de pasta e papel, incluindo resíduos } \\
\text { sólidos e licor negro. }\end{array}$ \\
\hline & $\begin{array}{l}\text { (SP5) Outros } \\
\text { subprodutos } \\
\text { provenientes de } \\
\text { outras indústrias } \\
\text { florestais }\end{array}$ & $\begin{array}{l}\text { Subprodutos de processamento de matérias-primas } \\
\text { florestais não-lenhosas, como por exemplo os as cascas } \\
\text { resultantes da transformação de transformação de } \\
\text { pinhão, frutos secos e os resíduos da indústria da cortiça. }\end{array}$ \\
\hline & $\begin{array}{l}\text { (MR) Madeira } \\
\text { recuperada } \\
\text { recovered post- } \\
\text { consumer wood }\end{array}$ & $\begin{array}{l}\text { Mobiliário, material utilizado na construção, embalagens } \\
\text { de madeira. }\end{array}$ \\
\hline & $\begin{array}{l}\text { (PR) Pastas } \\
\text { recuperadas e papel } \\
\text { recuperado } \\
\text { recovered fibre pulp } \\
\text { recovered paper }\end{array}$ & $\begin{array}{l}\text { Pastas secundárias provenientes do processo de fabrico } \\
\text { de pasta de papel; Embalagens de cartão ou papel } \\
\text { recuperadas; Papel recuperado. }\end{array}$ \\
\hline
\end{tabular}

Em relação às utilizações da biomassa florestal, adaptou-se uma taxonomia desenvolvida na Strategic Innovation and Research Agenda (SIRA) ((BIO-BASED INDUSTRY CONSORTIUM, 2013), que define as categorias principais de produtos e mercados numa lógica de bioeocomia que vai para além das utilizações tradicionais para produção de bioenergia: 
i. Bioenergia (BEne): Energia renovável proveniente da transformação química da biomassa

ii. Biocombustíveis (BComb): Combustíveis produzidos diretamente ou indiretamente a partir de biomassa (FAO).

iii. Bioprodutos (BProd), incluindo bioquímicos ou biomateriais.

Nos estudos setoriais que consideram toda a cadeia de valor dos produtos florestais, considera-se uma categoria adicional "Produtos das indústrias de base florestal", que poderão subdividir-se em produtos das indústrias de transformação $1^{\mathrm{a}}, 2^{\mathrm{a}}, 3^{\mathrm{a}}$, pasta e papel e outras.

Para realizar a análise dos fluxos de abastecimento e estabelecer o défice/excedente de material, é necessário distinguir entre o volume de biomassa florestal existente - ou potencial - e o que efetivamente é usado ou está em condições de ser usado - o mobilizável - sendo que a diferença entre ambos corresponde a perdas. Numa lógica de economia circular, as perdas deverão ser minimizadas ao longo dos processos. Assim, definem-se as seguintes tipologias de fluxos de biomassa florestal:

Biomassa potencial (BP): volume total de biomassa florestal de fontes primárias que teoricamente estará disponível para ser utilizada pelos diversos processos que recorrem à biomassa florestal para satisfazer as suas necessidades, isto é, a quantidade de biomassa total produzida. No presente trabalho, para a sua quantificação, descrita no ponto 2), consideram-se as tipologias e respetivas fontes de informação identificadas no Quadro 2.

Biomassa mobilizável (BM): volume total de biomassa florestal que é técnica e economicamente mobilizável e que, portanto, corresponderá à oferta total disponível para a indústria florestal e outros tipos de consumidores. Corresponde à BP subtraindo a biomassa que está em áreas abaixo do limiar de explorabilidade, como por exemplo áreas que apresentam elevado declive, áreas longe dos centros de consumo, áreas que apresentem condicionalismos legais. Inclui madeira queimada que possa ser explorada para qualquer fim, mas exclui a madeira deteriorada e a mortalidade provocada pelos incêndios ou outras causas naturais. A quantidade de BM seria igual à BP numa situação limite em que efetivamente toda a biomassa produzida seria mobilizada e em condições de ser utilizada. A relação entre a BP, os valores dos acréscimos de volume anuais, as perdas e BM permite ter a perceção se os recursos estão a ser usados para além da capacidade de regeneração das florestas, ou se, pelo contrário, 
haverá ainda margem para aumentar os consumos atuais, tendo em conta a crescente procura.

Quadro 3 - Resumo das fontes de informação usadas para estimar os fluxos de biomassa florestal

\begin{tabular}{|c|c|c|}
\hline Categoria & Estado & Fonte de informação \\
\hline \multicolumn{3}{|c|}{ Categorias de biomassa florestal } \\
\hline \multirow{3}{*}{$\begin{array}{l}(\mathrm{TM}) \text { Toros de } \\
\text { madeira }\end{array}$} & Biomassa potencial & Estimado a partir de dados do IFN5 \\
\hline & Biomassa mobilizável & $\begin{array}{l}\text { Estatísticas Agrícolas (EA), Quadro 3.2, (INE, } \\
\text { 2018), extraindo os consumos das várias } \\
\text { indústrias florestais }\end{array}$ \\
\hline & Biomassa consumida & $\begin{array}{l}\text { Fontes diversas: Estatísticas Agrícolas (EA), } \\
\text { Quadro } 3.2 \text { (INE, 2018); Informação } \\
\text { disponibilizada pela DGEG e ANPEB }\end{array}$ \\
\hline $\begin{array}{l}\text { (CE) Culturas } \\
\text { energéticas }\end{array}$ & Biomassa potencial & Estimativas obtidas no projeto S2BIOM \\
\hline \multirow[t]{2}{*}{ (L) Lenha } & Biomassa mobilizável & $\begin{array}{l}\text { Estatísticas Agrícolas (EA), Quadro } 3.2 \text { "lenha", } \\
\text { (INE, 2018) }\end{array}$ \\
\hline & Biomassa consumida & Informação disponibilizada pela DGEG \\
\hline \multirow{2}{*}{$\begin{array}{l}\text { (MT e SC) Matos e } \\
\text { vegetação sobcoberto }\end{array}$} & Biomassa potencial & $\begin{array}{l}\text { Equação de matos de Pereira et al. } \\
\text { Sobcoberto: Valores de referência de } \\
\text { Fernandes, } 2009\end{array}$ \\
\hline & Biomassa mobilizável & $\begin{array}{l}\text { Plano Nacional para a Promoção das } \\
\text { Biorrefinarias }\end{array}$ \\
\hline \multirow{3}{*}{$\begin{array}{l}\text { (RF) Resíduos } \\
\text { florestais }\end{array}$} & Biomassa potencial & Estimado a partir de dados do IFN5 e EA \\
\hline & Biomassa mobilizável & $\begin{array}{l}\text { Estimado a partir de dados do IFN5, EA e } \\
\text { IRENA }\end{array}$ \\
\hline & Biomassa consumida & Informação disponibilizada pela DGEG \\
\hline \multirow{3}{*}{$\begin{array}{l}\text { (SP) Subprodutos } \\
\text { das indústrias } \\
\text { florestais }\end{array}$} & Biomassa potencial & Valor desconhecido \\
\hline & Biomassa mobilizável & Estimado a partir de várias fontes \\
\hline & Biomassa consumida & $\begin{array}{l}\text { Informação disponibilizada pela DGEG e } \\
\text { ANPEB }\end{array}$ \\
\hline \multirow{2}{*}{$\begin{array}{l}\text { (MR) Madeira } \\
\text { recuperada }\end{array}$} & Biomassa mobilizável & $\begin{array}{l}\text { Estatísticas do Ambiente (INE, 2017), (Quadro } \\
\text { 5.9), INE, } 2017\end{array}$ \\
\hline & Biomassa consumida & Informação disponibilizada pela DGEG \\
\hline $\begin{array}{l}\text { (PR) Pastas } \\
\text { recuperadas e o } \\
\text { papel recuperado }\end{array}$ & Biomassa mobilizável & $\begin{array}{l}\text { Estatísticas do Ambiente, (Quadro 5.9), INE, } \\
2017\end{array}$ \\
\hline \multicolumn{3}{|c|}{ Categorias de utilização e tipos de produtos/mercados da biomassa florestal } \\
\hline $\begin{array}{l}\text { (EEC) Energia } \\
\text { elétrica e calor }\end{array}$ & $\begin{array}{l}\text { Quantidade } \\
\text { produzida }\end{array}$ & Informação disponibilizada pela DGEG \\
\hline $\begin{array}{l}\text { (PB) Pellets e } \\
\text { briquetes }\end{array}$ & $\begin{array}{l}\text { Quantidade } \\
\text { produzida }\end{array}$ & Informação disponibilizada pela ANPEB \\
\hline (L) Lenha & $\begin{array}{l}\text { Quantidade } \\
\text { produzida }\end{array}$ & $\begin{array}{l}\text { Estatísticas Agrícolas (EA), Quadro } 3.2 \text { "lenha", } \\
\text { (INE, 2018) }\end{array}$ \\
\hline $\begin{array}{l}\text { (BComb) Bio- } \\
\text { combustiveis }\end{array}$ & $\begin{array}{l}\text { Quantidade } \\
\text { produzida }\end{array}$ & Sem dados \\
\hline (BProd) Bio-produtos & $\begin{array}{l}\text { Quantidade } \\
\text { produzida }\end{array}$ & Sem dados \\
\hline
\end{tabular}

(1) Estimativa para as espécies de pinheiro bravo e eucalipto 
Biomassa consumida (BC): volume total de biomassa florestal que é efetivamente rececionado para transformação nos centros de consumo. Para efeitos de generalização e numa lógica de economia circular, faz-se a distinção entre consumo industrial (BC1), que pode ser subdividido em BC1_1 - Consumo pelas indústrias de base florestal e BC1_2 - Consumo para a produção de bioenergia; e consumo final (BC2), que irá originar resíduos do pós-consumo de materiais de base lenhosa que poderão ser reintroduzidos nos ciclos de valorização da biomassa florestal.

Procura potencial (PP): volume total de biomassa florestal que será necessário rececionar para que todos os centros de consumo estejam a funcionar na sua máxima capacidade. De notar que a BP poderá exceder a BC quando existe parte da capacidade de transformação que não é usada, por exemplo, se as centrais de biomassa estiverem paradas por falta de abastecimento.

Biomassa secundária potencial e mobilizável/utilizável: volume total de biomassa com origem nos subprodutos das indústrias de base-florestal ou resíduos lenhosos pós-consumo que é efetivamente reintroduzido no processo de transformação da biomassa. Tal como na biomassa com origem em fontes primárias, poderá distinguir-se entre a disponibilidade potencial (correspondente à produção total de subprodutos e material de pósconsumo) e o mobilizável/utilizável (correspondente à fração do total que efetivamente é reintroduzido no processo de transformação).

Assim, na análise global dos fluxos, o balanço total de biomassa (BTB) pode ser calculado como sendo a diferença entre o que é produzido [correspondente à biomassa mobilizável de fontes primárias (BFP) e secundárias (BFS)] e o consumo - correspondente à biomassa total consumida incluindo o consumo industrial (BC1), somando a diferença entre as importações (I) e as exportações (E). Assim, o BTB é dado por:

$$
\mathrm{BTB}=\mathrm{BFP}+\mathrm{BFS}-\mathrm{BC} 1+\mathrm{I}-\mathrm{E}
$$

Quando a produção acrescida das I e subtraída das E, excede o consumo isso pode indicar excesso de oferta, mas se exceder a procura potencial, então deverá mesmo tratar-se de uma situação de excesso de oferta. O que dará origem a stocks de madeira cortada que ficam para o ano seguinte, uma fração da qual se poderá deteriorar. Inclui também material lenhoso que não é removido da floresta mesmo tendo atingido o seu limiar de explorabilidade.

A Figura 2 apresenta um esquema conceptual para caracterização dos fluxos de biomassa florestal, tendo por base os conceitos anteriormente apresentados. 


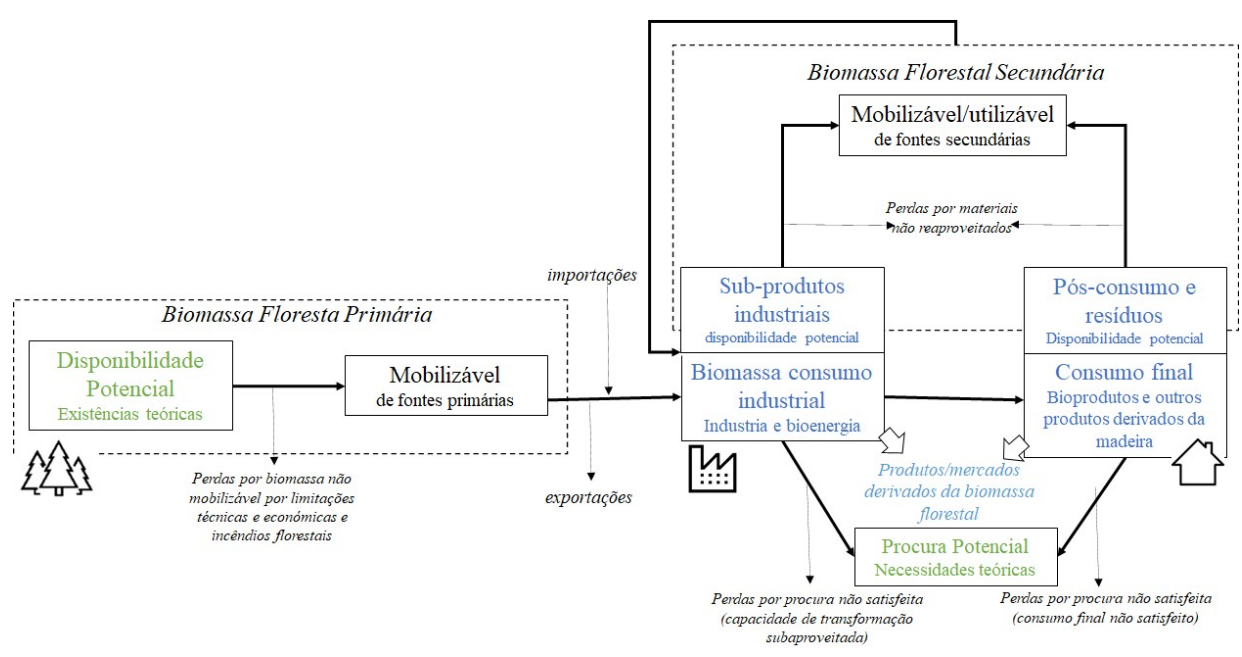

Figura 2 - Esquema conceptual para caracterização dos fluxos de biomassa florestal

2) Análise de dados estatísticos e obtenção de estimativas de fluxos de biomassa

Apesar dos conceitos de biomassa potencial, mobilizável e consumida serem significativamente diferentes, na prática, os métodos usados em Portugal para a quantificação dos fluxos de biomassas e os respetivos dados obtidos, em alguns casos, não permitem fazer uma clara distinção entre estes. O Quadro 2 refere as fontes de informação utilizadas para cada uma das categorias para o ano 2016 que é o ano de referência do estudo.

\section{Biomassa potencial:}

Toros de madeira (TM): A estimativa da biomassa potencial da componente arbórea que irá originar os toros de madeira é estimada para as duas principais espécies com interesse comercial - Pinheiro bravo e Eucalipto - que representam cerca de $64 \%$ do volume total em crescimento. A estimativa tem por base os "Volumes em crescimento por espécie florestal" do Inventário Florestal Nacional (tabela 302.PTC do IFN6); adicionando os acréscimos médios anuais para povoamentos puros, mistos dominantes e mistos dominados (Quadro 306.PTC do IFN5); e subtraindo as perdas devido aos incêndios em 2015, obtidos a partir de estatísticas do ICNF. O valor estimado de biomassa potencial para pinheirobravo e eucalipto em 2016 é 108084 mil m³ ( $^{2} \mathbf{8 2 7 0 8}$ mil ton) (Quadro 3). 
Quadro 4 - Estimativa da biomassa potencial para pinheiro bravo e eucalipto para 2016

\begin{tabular}{|c|c|c|c|c|c|}
\hline Espécie & $\begin{array}{c}\begin{array}{c}\text { Volume } \\
\text { cresc. } 2015 \\
\left(\times 10^{3} \mathrm{~m}^{3}\right)\end{array}\end{array}$ & $\begin{array}{l}\text { Acréscimo } \\
\text { médio } \\
\text { anual } \\
\mathrm{m}^{3} / \text { ha.ano }\end{array}$ & $\begin{array}{l}\text { Área } 2015 \\
\left(\times 10^{3} \mathrm{ha}\right)\end{array}$ & $\begin{array}{c}\text { Área } \\
\text { ardida2015 } \\
\left(\times 10^{3} \mathrm{ha}\right)\end{array}$ & $\begin{array}{c}\text { Biomassa } \\
\text { potencial } \mathbf{T M}_{2016}{ }^{(1)} \\
\left(\times 10^{3} \mathrm{~m}^{3}\right)\end{array}$ \\
\hline $\begin{array}{l}\text { Pinheiro- } \\
\text { bravo }\end{array}$ & 61610 & 3,0 & 615 & 7,2 & 63433,40 \\
\hline \multirow[t]{2}{*}{ Eucalipto } & 41020 & 4,8 & 766 & 9,6 & 44650,72 \\
\hline & & & & & 108084,12 \\
\hline
\end{tabular}

(1) $\mathrm{BP}_{2016}=$ Volume em cresc2015 + AMA (Area2015 - Área ardida2015)

Culturas energéticas (CE): Em Portugal, as CE são escassas e de âmbito experimental. Têm sido realizados estudos que permitem compreender os fatores que influenciam a sua rentabilidade, tais como a espécie usada, sistemas de cultivo, manutenção, gestão de água, entre outros, de forma a potenciar a expansão a curto prazo das culturas energéticas lenhosas no nosso país (PATRÍCIO et al., 2013). De acordo com o projeto S2BIOM a biomassa potencial proveniente destas culturas em Portugal é de 77 mil ton. Correspondendo principalmente a povoamentos de choupo, mas que atualmente não têm tido utilização significativa.

Matos e vegetação sobcoberto (MT): A biomassa potencial em matos pode ser estimada pela equação proposta por PEREIRA et. al., 2006. De acordo com esta equação, assume-se que a partir dos 10 anos após a ocorrência do último fogo, o acréscimo de biomassa é pouco significativo. Durante este período, a biomassa acumulada é de 19 ton/ha, o que em média corresponde a 1.9 ton/ha/ano. De acordo com o IFN6, a área de matos, em 2015, representava 2,7 milhões de ha. $\mathrm{Na}$ falta de dados, assume-se que existe uma distribuição homogénea do estrato matos pelas idades compreendidas entre 0 e 10 anos (i.e., 245,5 mil ha em cada uma das classes de idade). Assim, aplica-se a equação anterior a cada idade (dos 0 aos 10) e multiplica-se pela respetiva área, a fim de obter a estimativa de biomassa total para cada classe de idade considerada. A soma das estimativas das várias classes de idade permite chegar ao valor de biomassa total de matos na ordem dos 30,8 milhões de ton. Ressalva-se que deste valor, só uma fração poderá ser explorada, podendo-se admitir que só a quantidade anual acumulada de biomassa será aquela que representa potencial para 
aproveitamento de forma sustentável. Assim, pela aplicação da equação anterior, o valor acumulado anual seria de 1,9 ton/ha/ano. Multiplicando este valor pela área de matos refletida no IFN6, em 2015, verificou-se uma acumulação anual de 5,26 milhões de toneladas/ano.

A biomassa potencial em sobcoberto (i.e. arbustos, matos e herbáceas existente nos povoamentos florestais) para 2016 pode estimar-se a partir dos volumes médios de biomassa em sobcoberto (ton/ha) publicados por (FERNANDES, 2009) (BSC) e dos dados de ocupação por estas espécies do IFN6, considerando ainda as perdas provocadas pelos incêndios florestais, apresentados no Boletim Estatístico da Celpa de 2017 (Quadro 4). O que corresponderá a um valor de biomassa potencial de 5010,6 mil ton.

Quadro 4 - Estimativa da biomassa potencial em sobcoberto para 2016

\begin{tabular}{|c|c|c|c|c|}
\hline Espécie & $\begin{array}{c}\text { Biomassa em } \\
\text { sub-coberto } \\
\left(\mathrm{B}^{\mathrm{sc}}\right) \\
\left(\times 10^{3} \text { ton } / \mathrm{ha}\right)\end{array}$ & $\begin{array}{l}\text { Área } 2015 \\
\left(x 10^{3} \mathrm{ha}\right)\end{array}$ & $\begin{array}{c}\text { \% da área } \\
\text { afetada por } \\
\text { incêndios } 2015\end{array}$ & $\begin{array}{c}\text { Biomassa } \\
\text { potencial sob- } \\
\text { coberto }_{2016}(1) \\
\left(\times 10^{3} \text { ton }\right)\end{array}$ \\
\hline Acácia & 3,47 & 8 & $12 \%$ & 24,43 \\
\hline Eucalipto & 1,96 & 766 & $16,8 \%$ & 1466,08 \\
\hline Pinheiro & 3,16 & 615 & $17,9 \%$ & 1921,28 \\
\hline Sobreiro & 1,77 & 705 & $6,5 \%$ & 1247,85 \\
\hline $\begin{array}{l}\text { Outros } \\
\text { carvalhos }\end{array}$ & 4,89 & 77 & $6,5 \%$ & 350,93 \\
\hline & & & & 5010,56 \\
\hline
\end{tabular}

(1) $\mathrm{BPSC}_{2016}=\mathrm{Bsc} \times$ Area2015 (1 -\% área afetada por incêndios 2015)

Quadro 5 - Estimativa da biomassa potencial em resíduos florestais para 2016

\begin{tabular}{cccccc}
\hline Espécie & $\begin{array}{c}\text { Volume } \\
\text { total IFN5 } \\
\left(\times 10^{3} \mathrm{~m}^{3}\right)\end{array}$ & $\begin{array}{c}\text { Vol } \\
\text { mercantil } \\
\text { IFN5 } \\
\left(\times 10^{3} \mathrm{~m}^{3}\right)\end{array}$ & \% RF ${ }^{(1)}$ & $\begin{array}{c}\text { Madeira } \\
\text { removida2016 } \\
\left(\times 10^{3} \mathrm{~m}^{3}\right)\end{array}$ & $\begin{array}{c}\text { Biomassa } \\
\text { potencial } \\
\mathbf{R F}_{2016^{(2)}} \\
\left(\times 10^{3} \mathrm{~m}^{3}\right)\end{array}$ \\
\hline $\begin{array}{c}\text { Pinheiro- } \\
\text { bravo }\end{array}$ & 84625 & 60813 & $28 \%$ & 3836 & 1074,1 \\
Eucalipto & 44228 & 33122 & $25 \%$ & 8154 & 2038,5 \\
\hline
\end{tabular}

$\begin{array}{ll}\text { (1) } \% F R=\left(1-\frac{\text { Vol mercantil }}{\text { Vol total }}\right) \times 100 & \text { (2) } \mathrm{BPRF}_{2016}=\text { Madeira removida } 2015_{2} \% \mathrm{RF}\end{array}$ 
Assume-se que os resíduos florestais correspondem a 25\% e $28 \%$ do volume total, o que está dentro da ordem de grandeza dos valores encontrados na literatura, e.g. KARJALAINEN et al., 2004 estima que nos sistemas convencionais de exploração florestal, cerca de $60 \%$ da árvore é utilizada para fins industriais e $40 \%$ são resíduos. Estimou-se um valor biomassa potencial de 3112,6 mil ton. Este valor é subestimado porque não considera os cepos nem outros resíduos como a proveniente da gestão dos povoamentos, incluindo árvores de pequeno porte removidas em desbastes e do material lenhoso resultante de cortes fitossanitários, de medidas de defesa da floresta contra os incêndios, e do controlo de áreas com invasoras lenhosas, para os quais não se encontraram dados.

\section{Biomassa mobilizável:}

Toros de madeira (TM): De acordo com Estatísticas Agrícolas (EA), Quadro 3.2 (INE, 2018), o volume total de TM mobilizável em Portugal Continental em 2016 foi de $11990 \mathrm{mil} \mathrm{m}^{3}$ ( $\approx 9366,70$ mil toneladas) considerando o total de coníferas e folhosas, correspondendo à diferença entre os valores apresentados para "total madeira removida" e "lenha". Desta quantidade, apenas uma pequena parte residual poderá ser usada para biomassa, dado que os TM se destinam primordialmente ao abastecimento das indústrias florestais. Deste volume, a fração efetivamente disponível de biomassa pode ser estimada subtraindo os consumos das indústrias florestais, obtendo-se um valor de $2148 \mathrm{mil} \mathrm{m}^{3}(\approx \mathbf{8 1 5 , 6}$ mil toneladas):

- A indústria da produção de madeira serrada, consumiu em 2016 cerca de 2072 mil m3 de madeira sem casca, dados EA, Quadro 3.2 "madeira para serração", (INE, 2018). De acordo com LOURO et al., 2013 este valor corresponderá a cerca de $12 \%$ do consumo total interno. A produção de madeira serrada no ano de 2016 foi de $1085 \mathrm{mil} \mathrm{m}^{3}$ ( $\approx \mathbf{6 8 3}, \mathbf{4}$ mil toneladas).

- A indústria da produção de painéis de madeira consumiu em 2016 cerca de $680 \mathrm{mil} \mathrm{m3}$ ( $\approx 504$ mil toneladas) de madeira sem casca (CENTRO PINUS, 2017). A produção total de painéis de partículas de madeira, painéis de fibra de madeira, folheados, contraplacados, lamelados e outros painéis foi de $1243 \mathrm{mil} \mathrm{m}^{3}$ (ح964,4 mil toneladas), dados das EA - Quadro 3.3 "painéis de madeira" (INE, 2018).

- A indústria da produção de pasta para produção de papel consumiu em 2016 cerca de $7795 \mathrm{mil} \mathrm{m}^{3} /$ ano de madeira sem casca $(\approx 7142,30 \mathrm{mil}$ toneladas) (dados do boletim estatístico 2017, Celpa, Tabela 3.2., pág. 37). Em 2016, este valor terá representado cerca de $88 \%$ do consumo interno de 
toros de madeira, com uma produção total de pasta de madeira de $\mathbf{2 7 2 9}$ mil toneladas, dados das EA, Quadro 3.3 "pastas químicas" (INE, 2018).

- O consumo para outros fins industriais, tais como madeira em bruto e postes, foi de $282 \mathrm{mil} \mathrm{m}^{3}$ /ano de toros de madeira ( $\approx 221,4$ mil toneladas) EA, Quadro 3.2 "Outras madeiras redondas industriais" (INE, 2018).

Lenha (L): De acordo com Estatísticas Agrícolas (EA), Quadro 7.3 "lenha", o volume total de lenha mobilizável em Portugal Continental em 2016 foi de 1092 mil m³, correspondendo a $\mathbf{7 6 4}$ mil toneladas, assumindo um fator de conversão médio de 0,7 .

Matos e vegetação sobcoberto (MT): O Plano Nacional para a Promoção das Biorrefinarias, publicado pela Resolução do Conselho de Ministros n. ${ }^{0}$ 163/2017, estima uma quantidade total para este tipo de resíduos de $441 \mathrm{mil}$ toneladas/ano para o caso das espécies verdes herbáceas e de 1025 mil toneladas/ano no caso dos matos, totalizando 1466 mil toneladas/ano disponíveis para aproveitamento com vista à produção de bioenergia e outros bio produtos. Neste plano não está, no entanto, discriminada a fonte de dados que serviu de base ao seu cálculo. No caso do sob-coberto não foram encontradas fontes bibliográficas que permitam quantificar a biomassa mobilizável.

Resíduos florestais (RF): Não existindo dados nas estatísticas oficiais relativos à biomassa mobilizável de resíduos florestais, estimou-se este valor a partir da biomassa potencial (Quadro 5), considerando que cerca de 50\% do total de resíduos florestais podem ser efetivamente mobilizados (IRENA, 2019) atendendo a questões relacionadas com a preservação dos solos e também limitações técnicas e financeiras. Obtivemos assim um valor total resíduos florestais mobilizáveis de $\mathbf{1 0 8 9}, \mathbf{4}$ mil toneladas, valor esse que será utilizado no cálculo dos balanços globais.

Subprodutos das indústrias florestais Industriais (SP): Neste estudo, estimouse o volume mínimo de cada tipo de sobrantes industriais com base em informação estatística referente a 2016, dispersa por várias fontes, nomeadamente:

-(SP1) 1402,39x103 ton de aparas e estilhas de madeira (EA-INE 2018 ("Produção de produtos derivados da madeira"). Quadro 3_3)

- (SP2 e SP3) 496,84 x1033 ton de estilha, serradura e pó da lixagem (EAmbiente-INE 2017 ("Resíduos setoriais não perigosos por atividades económicas" Quadro 5_7)) 
- (SP4) 3669,60 x103 ton de licor negro para produção de energia elétrica e calor (DGEG, 2018. Comunicação pessoal)

- (SP5) 358,00 x10³ ton de esperdícios de cortiça, cortiça triturada, granulada, pulverizada (DAPFVRS/DGPF-ICNF. Fileiras Florestais ${ }^{3}$ )

Obteve-se um valor total de 5926,83 mil toneladas/ano. Os dados disponibilizados pelo projeto S2BIOM estimaram para 2012, a quantidade de SB produzidos na ordem das 3580 mil toneladas/ano, valor este que poderemos considerar atendendo aos consumos para produção de bioenergia apresentados na secção seguinte deste relatório.

Material Lenhoso Pós-Consumo (PC): De acordo com as Estatísticas do Ambiente (INE, 2017), foram produzidos 315,7 mil toneladas em 2016 e $350 \mathrm{mil}$ toneladas em 2017 de resíduos de madeira não perigosos (Quadro 5.9 - Resíduos setoriais por categorias). Nesta categoria são igualmente consideradas as pastas recuperadas e o papel recuperado (PR) que entram novamente no processo de fabrico de papel reciclado. De acordo com as Estatísticas do Ambiente, INE, 2017 (Quadro 5.9), nesse ano foram produzidas 752,7 mil toneladas de Resíduos não perigosos de papel e cartão. Quanto à questão da pasta recuperada, em 2016 correspondeu a um valor de $\mathbf{3 1 6 , 1}$ mil toneladas. Na fileira da pasta e do papel, a recuperação e reciclagem de papel representa, igualmente, um importante recurso de matéria-prima. Em 2016, a produção de pastas de fibra secundária e papel para reciclar para integração em papel foi de 197 mil toneladas (cerca de 13,4\% da produção total), (CELPA, 2018).

\section{Consumo de biomassa florestal}

Consumo de biomassa florestal para produção de bioenergia: Em 2017, existiam em Portugal 12 centrais a biomassa dedicadas (produção de energia elétrica) e 9 centrais em cogeração (produção combinada de energia elétrica e de energia térmica), totalizando uma capacidade instalada de cerca de 525MW. Em 2016 a produção total de calor e energia elétrica em centrais de biomassa foi de 2481GWh, e em 2017 de 2570GWh de acordo com os dados estatísticos da DGEG, 2018, correspondendo a uma capacidade instalada do conjunto de 534,69MW (http://e2p.inegi.up.pt/\#Tec2).

\footnotetext{
${ }^{3} \mathrm{http}: / /$ www2.icnf.pt/portal/florestas/fileiras/resource/doc/fileirassilvoindustriais15set2017.pdf
} 
Para os cálculos do consumo de biomassa florestal para a produção de bioenergia, este estudo recorreu aos dados estatísticos produzidos pela DGEG. Em 2016, o consumo total de biomassa para a produção de energia elétrica e vapor foi de 5,8 milhões de toneladas. Cerca de 5,77 milhões de toneladas são biomassa florestal e o restante são subprodutos e resíduos das indústrias agrícolas, nomeadamente o bagaço de azeitona (26,45 mil toneladas) e o bagaço de uva (464 toneladas). Realça-se a predominância de consumo de subprodutos das indústrias de transformação de madeira (4670 mil toneladas, $81 \%$ do consumo total de biomassa florestal), seguido de resíduos florestais $(578,2 \mathrm{mil}$ toneladas, $10 \%$ do consumo total), de toros de madeira (429 mil toneladas, 7,4\% do consumo total) e lenha (88 mil toneladas, 1,5\% do consumo total). Em relação aos toros de madeira para produção de energia, 62,5\% (268232 toneladas) provêm de madeira triturada de diversas espécies (tais como pinheiro, eucalipto, acácia, choupo), 27,6\% (118319 toneladas) provêm de rolaria de eucalipto e 9,8\% (42158 toneladas) provêm de rolaria de pinheiro. O consumo de material lenhoso pós-consumo para produção de bioenergia é muito baixo, como esperado, atendendo aos elevados níveis de reintrodução destes materiais nos processos de fabrico do subsector das pastas e papel e dos painéis. Ainda de acordo com a informação estatística produzida pela DGEG, em 2016 o consumo de biomassa florestal em centrais dedicadas foi de 1331,4 mil toneladas, enquanto nas centrais em cogeração foi de 4464,6 mil toneladas, totalizando cerca de 5,79 milhões de toneladas. Relativamente ao processo de produção de pellets, em 2016 foram consumidas cerca de 1212 mil toneladas de biomassa (ANPEB, comunicação pessoal), cujo processo, em média, utiliza 32\% de matériaprima proveniente de SPM (cerca de 387,840 mil toneladas) e os restantes $68 \%$ é proveniente de toros de madeira (TM), cerca de 824,160 mil toneladas, essencialmente de pinheiro bravo ${ }^{4}$, sendo a eficiência do processo de cerca de $50 \%$, resultando numa produção de 606 mil toneladas de pellets (Quadro 6).

\section{3) Representação dos fluxos através de um Diagrama de Sankey}

Ressalvando as questões associadas à dificuldade de encontrar dados que permitissem proceder a cálculos mais rigorosos quanto à disponibilidade de biomassa florestal e da dificuldade de interpretação de alguns dados consultados devido à falta de meta dados, verificamos a existência de um balanço positivo para a disponibilidade de biomassa na ordem dos 1,64 milhões de toneladas (Quadro 7) para o ano de 2016 em análise. Para este cálculo, não

$4720000 \mathrm{~m}^{3} \mathrm{~s} / \mathrm{c}$ (CENTRO PINUS, 2017); $730000 \mathrm{~m}^{3} \mathrm{~s} / \mathrm{c}$ em 2017 (CENTRO PINUS, 2017) 
foram considerados os matos nem a biomassa em sobcoberto, uma vez que atualmente os mesmos não são utlizados.

Quadro 6 - Quantidade consumida de biomassa florestal, em 2016, para a produção de energia, por categoria

\begin{tabular}{|c|c|c|}
\hline $\begin{array}{l}\text { Tipo de biomassa } \\
\text { florestal }\end{array}$ & $\begin{array}{c}\text { Quantidade consumida } \\
\text { (x1000 ton) }\end{array}$ & Designação usada pela DGEG \\
\hline $\begin{array}{l}\text { Consumo em centrais } \\
\text { dedicadas e } \\
\text { cogeração: }\end{array}$ & 5796,00 & \\
\hline $\begin{array}{l}(\mathrm{TM}) \text { Toros de } \\
\text { madeira }\end{array}$ & 429,10 & 1.1. Rolaria de madeira \\
\hline $\begin{array}{l}\text { (CE) Culturas } \\
\text { energéticas florestais }\end{array}$ & - & Sem correspondência direta \\
\hline (L) Lenha & & Sem correspondência direta \\
\hline $\begin{array}{l}\text { (MT) Matos e } \\
\text { Sobcoberto }\end{array}$ & - & Sem correspondência direta \\
\hline $\begin{array}{l}\text { (RF) Resíduos } \\
\text { florestais }\end{array}$ & 666,49 & $\begin{array}{l}\text { 1.2. Resíduos de operações } \\
\text { florestais (ramagens, cascas, } \\
\text { cepos, etc.) }\end{array}$ \\
\hline $\begin{array}{l}\text { (SP1 a SP4) } \\
\text { Subprodutos das } \\
\text { indústrias florestais }\end{array}$ & 4670,26 & $\begin{array}{l}\text { 2. Subprodutos e resíduos da } \\
\text { indústria de processamento da } \\
\text { madeira }\end{array}$ \\
\hline $\begin{array}{l}\text { (SP5) Outros } \\
\text { subprodutos }\end{array}$ & 1,63 & 6.4. Cascas rijas e sementes \\
\hline $\begin{array}{l}\text { (MR) Madeira } \\
\text { recuperada }\end{array}$ & 1,05 & $\begin{array}{l}\text { 4. Madeira usada -> madeira sem } \\
\text { tratamento químico }\end{array}$ \\
\hline $\begin{array}{l}(P R) \text { Pastas } \\
\text { recuperadas e papel } \\
\text { recuperado }\end{array}$ & - & Sem correspondência direta \\
\hline $\begin{array}{l}\text { Outras Origens Não } \\
\text { Florestais }\end{array}$ & 26,92 & $\begin{array}{l}\text { 6. Subprodutos e resíduos da } \\
\text { indústria agroalimentar }\end{array}$ \\
\hline Pellets & 0,54 & $\begin{array}{l}\text { 3. Biomassa processada para } \\
\text { energia -> Pellets" }\end{array}$ \\
\hline $\begin{array}{l}\text { Consumo das } \\
\text { unidades de produção } \\
\text { de pellets: }\end{array}$ & 1212 & \\
\hline $\begin{array}{l}(\mathrm{TM}) \text { Toros de } \\
\text { madeira }\end{array}$ & 824,16 & $\begin{array}{l}68 \% \text { do valor total (ANPEB, } \\
\text { comunicação pessoal) }\end{array}$ \\
\hline $\begin{array}{l}\text { (SP) Subprodutos das } \\
\text { indústrias }\end{array}$ & 387,84 & $\begin{array}{l}32 \% \text { do valor total (ANPEB, } \\
\text { comunicação pessoal) }\end{array}$ \\
\hline
\end{tabular}


Algumas diferenças entre as entradas de material e a sua utilização pelos diversos processos poderão ser explicadas pela existência de stocks e por erros associados aos fatores de conversão utilizados para ser possível comparar os diferentes valores apresentados em sistemas de unidades diferentes. Este é um dos aspetos que deverá merecer atenção por parte das estatísticas oficiais, sendo desejável que as diversas entidades com responsabilidades na produção e publicação desenvolvam esforços no sentido de garantir que não existem discrepâncias entre os mesmos e que sejam disponibilizados de forma comparável, utilizando as mesmas unidades e explicitando os fatores de conversão utilizados.

Quadro 7 - Balanço total de biomassa florestal para Portugal 2016 (x10³ ton.)

\begin{tabular}{|c|c|c|c|c|c|c|c|c|c|c|}
\hline \multirow{2}{*}{ Categoria } & \multicolumn{2}{|c|}{ Produção } & \multicolumn{5}{|c|}{ Consumo } & \multirow{2}{*}{ I } & \multirow{2}{*}{ E } & \multirow{2}{*}{$\begin{array}{c}\text { BTB } \\
\text { (1) }\end{array}$} \\
\hline & potencial & mobilizável & (EEC) & $(\mathrm{PB})$ & (OUB) & (BC1_2) & (BC1_1) & & & \\
\hline (TM) & 82708,1 & 9366,7 & 429,1 & 824,2 & 0 & 1253,26 & 9335,8 & 2028,0 & 257,3 & 548,3 \\
\hline (CE) & 77,0 & 0 & 0 & 0 & 0 & 0 & 0 & 0 & & 0 \\
\hline (L) & - & 764,0 & 0 & 0 & 764,0 & 764,0 & 0 & 0 & & 0 \\
\hline (MT) & 5260,0 & 1025,4 & 0 & 0 & 0 & 0 & 0 & 0 & & - \\
\hline (SC) & 5010,6 & - & 0 & 0 & 0 & 0 & 0 & 0 & & - \\
\hline (RF) & 47185,0 & 1089,4 & 666,5 & 0 & 0 & 666,5 & 0 & 0 & & 422,9 \\
\hline (SP1) & & 1402,4 & 914,7 & 387,8 & 0 & 1388,5 & & 0 & & 13,8 \\
\hline (SP2) & & 411,2 & & & & & 411,2 & & & 0 \\
\hline (SP3) & & 85,6 & 85,6 & & & 85,6 & & & & 0 \\
\hline (SP4) & & 3669,5 & $\begin{array}{r}3 \\
669,5 \\
\end{array}$ & 0 & 0 & 3669,5 & 0 & 0 & & 0 \\
\hline (SP5) & & 358,0 & 1,6 & 0 & 0 & 1,6 & 0 & 0 & & 356,4 \\
\hline (MR) & & 151,0 & 1,0 & 0 & 0 & 1,0 & 150 & 0 & & 0 \\
\hline (PR) & & 752,7 & & 0 & 0 & 0 & 419,7 & 0 & & 333,0 \\
\hline
\end{tabular}

(1) BTB = BFP + BFS - BC1_1 - BC1_2 + I - E;

BFP - Biomassa Florestal Primária mobilizável, relativa: a TM - Toros de madeira; L - Lenha; MT Matos; SC - Sobcoberto; RF - Resíduos florestais; BFS - Biomassa Florestal Secundária mobilizável, relativa: SP1 - Subprodutos das indústrias de $1^{a}$ transformação; SP2 Subprodutos das indústrias de $2^{\mathrm{a}}$ transformação; SP3 Subprodutos das indústrias de $3^{\mathrm{a}}$ transformação; SP4 Subprodutos das indústrias de pasta e papel; SP5 Outros subprodutos provenientes de outras indústrias florestais; MR - Madeira recuperada; PR - Pastas recuperadas e papel recuperado;

BC1_1 Consumo total pela indústria e BC1_2 Consumo total para bioenergia, relativo a EEC Energia Elétrica e Vapor; PB - Pellets e briquetes; OUB - Outros Usos Bioenergéticos (e.g. Carvão vegetal, lenha, biocombustíveis; I - Importações; E - Exportações 


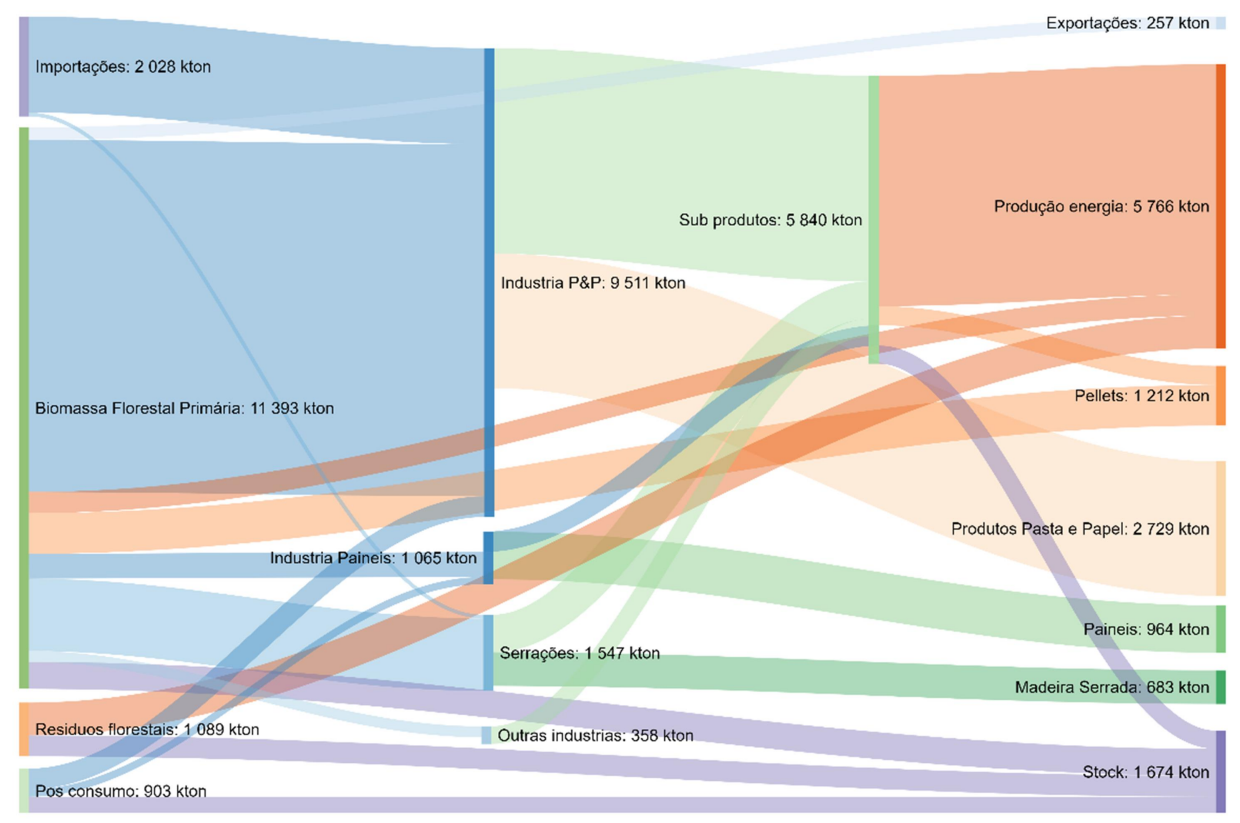

Figura 3 - Diagrama de Sankey dos fluxos de abastecimento da biomassa florestal em Portugal. Análise à escala de Portugal Continental para o ano de 2016

\section{4) Análise de cenários}

Considerando a metodologia apresentada, alguns cenários poderão ser construídos com vista a ajudar a compreender as incertezas relacionadas com a procura e oferta de biomassa florestal. Meramente de caracter indicativo, pois outros cenários poderão ser considerados, através de alterações, quer do lado dos inputs, quer do lado dos consumos, apresenta-se um cenário com vista à análise do impacto nos balanços globais de biomassa, com base em algumas das orientações das políticas nacionais e da tendência de investimento por parte da indústria:

I. Aumento do número de centrais dedicadas de produção de bioenergia, equivalendo a uma produção adicional em cerca de 116MW, de acordo com as iniciativas atualmente em curso e previstas num futuro próximo;

II. Aumento em $10 \%$ da capacidade de produção de pasta de papel em resposta ao crescimento verificado nos últimos anos; 
III. Introdução de biorrefinarias, com um consumo previsto de 100kton de biomassa florestal residual, tendo em consideração o previsto no Plano Nacional para a Promoção das Biorrefinarias.

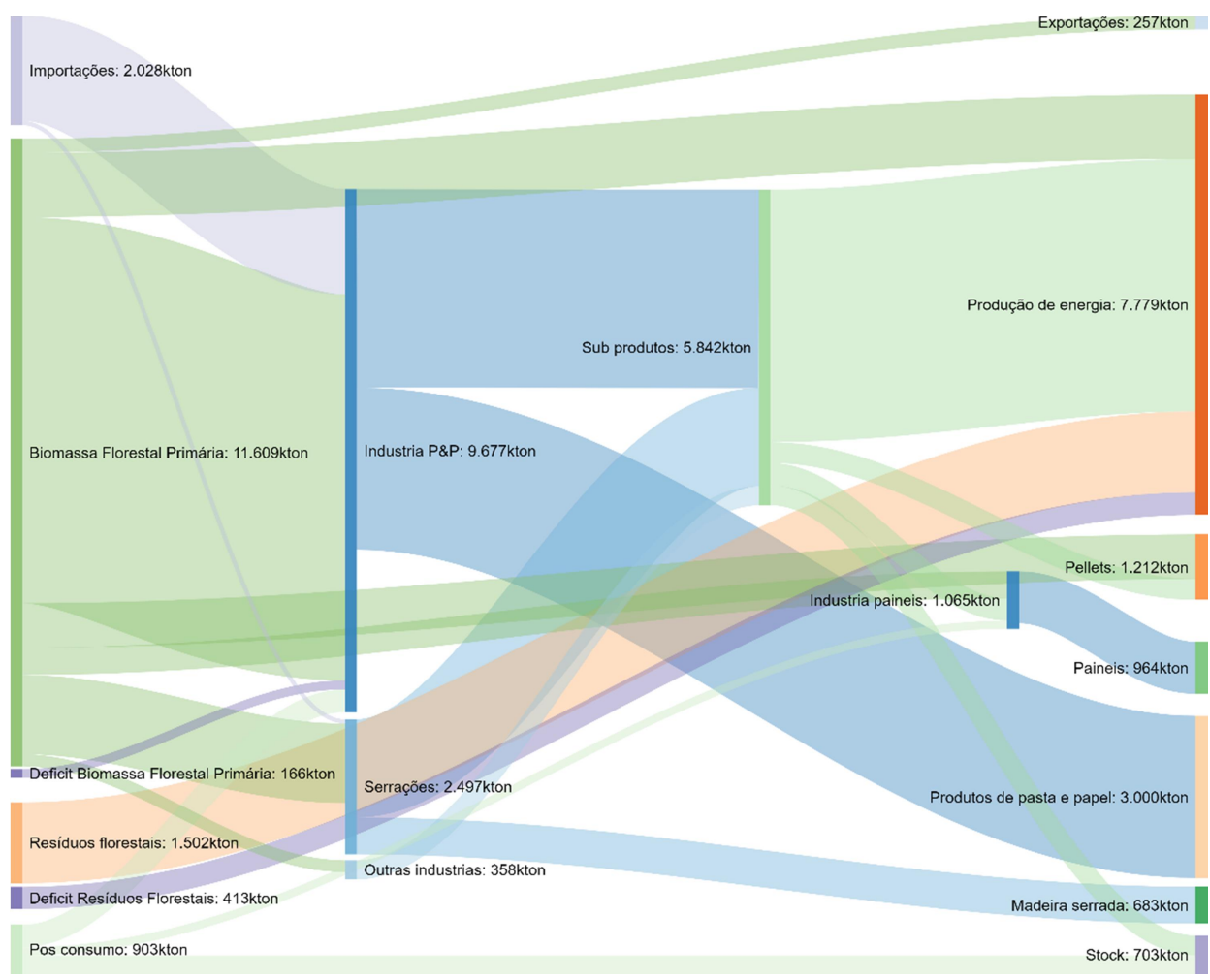

Figura 4 - Diagrama de Sankey para o cenário apresentado

Nestas condições, os resultados apontam para um défice no fornecimento de biomassa, especificamente relacionado com a escassez de biomassa florestal primária, incluindo madeira redonda, lenha, arbustos e resíduos florestais, que pode ser eventualmente compensado parcialmente por um excedente de material pós-consumo (Quadro 8). Neste caso, aumentar o consumo como previsto, são necessários esforços para garantir a necessária disponibilidade de recursos de madeira, por exemplo, aumentando a quantidade de madeira explorada ou a quantidade de madeira importada. Em ambos os casos, a sustentabilidade da utilização dos recursos e as questões económicas terão de ser devidamente consideradas. 
Quadro 8 - Comparação do balanço total de biomassa florestal para Portugal 2016 para a situação de referência (REF) e cenário analisado (x10³ ton.)

\begin{tabular}{|c|c|c|c|c|c|c|c|}
\hline \multirow{3}{*}{ Categoria } & \multirow{3}{*}{ 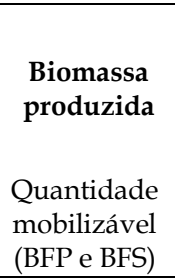 } & \multicolumn{4}{|c|}{ (BC) Biomassa consumida } & \multicolumn{2}{|c|}{$\begin{array}{c}\text { (BTB) Balanço } \\
\text { Total }\end{array}$} \\
\hline & & \multicolumn{2}{|c|}{$\begin{array}{c}\text { (BC1_2) Total Biomassa } \\
\text { para energia }\end{array}$} & \multicolumn{2}{|c|}{$\begin{array}{c}\text { (BC1_1) Consumo } \\
\text { para usos } \\
\text { industriais }\end{array}$} & \multirow[b]{2}{*}{$\begin{array}{r}\text { Situação } \\
\text { referência }\end{array}$} & \multirow[b]{2}{*}{ Cenário } \\
\hline & & $\begin{array}{l}\text { Situação } \\
\text { referência }\end{array}$ & Cenário & $\begin{array}{l}\text { Situação } \\
\text { referência }\end{array}$ & Cenário & & \\
\hline $\begin{array}{l}(\mathrm{TM}) \text { Toros de } \\
\text { madeira }^{1}\end{array}$ & 9366,70 & 1253,26 & 1253,26 & 9335,82 & 10050,05 & 548,32 & $-165,91$ \\
\hline $\begin{array}{l}\text { (CE) Culturas } \\
\text { energéticas } \\
\text { florestais }\end{array}$ & 0,00 & 0,00 & 0,00 & 0,00 & 0,00 & 0,00 & \\
\hline (L) Lenha & 764,00 & 764,00 & 764,00 & 0,00 & 0,00 & 0,00 & \\
\hline (MT) Matos & 1025,37 & 0,00 & 0,00 & 0,00 & 0,00 & - & \\
\hline (SC) Sobcoberto & 0,00 & 0,00 & 0,00 & 0,00 & 0,00 & - & 0,00 \\
\hline $\begin{array}{l}\text { (RF) Resíduos } \\
\text { florestais } \\
\text { (SP1) }\end{array}$ & 1089,40 & 666,49 & 1502,50 & 0,00 & 0,00 & 422,91 & $-413,10$ \\
\hline $\begin{array}{l}\text { Subprodutos } \\
\text { ind. serração }\end{array}$ & 1402,39 & 1388,55 & 1388,55 & & & 13,84 & 13,84 \\
\hline (SP2) Painéis & 411,21 & 0,00 & 0,00 & 411,21 & 411,21 & 0,00 & 0,00 \\
\hline $\begin{array}{l}\text { (SP3) Indústria } \\
\text { do Mobiliário } \\
\text { (SP4) }\end{array}$ & 85,63 & 85,63 & 85,63 & 85,63 & 85,63 & 0,00 & 0,00 \\
\hline $\begin{array}{l}\text { Subprodutos } \\
\text { pasta e papel }\end{array}$ & 3669,55 & 3669,55 & 3669,55 & 3669,55 & 3669,55 & 0,00 & 0,00 \\
\hline $\begin{array}{l}\text { (SP5) Outros } \\
\text { subprodutos }\end{array}$ & 358,00 & 1,63 & 1,63 & 1,63 & 1,63 & 356,37 & 356,37 \\
\hline $\begin{array}{l}\text { (MR) Madeira } \\
\text { recuperada }\end{array}$ & 151,05 & 1,05 & 1,05 & 150,00 & 150,00 & 0,00 & 0,00 \\
\hline $\begin{array}{l}(\mathrm{PR}) \text { Pastas e } \\
\text { papel } \\
\text { recuperado }\end{array}$ & 752,70 & 0,00 & 0,00 & 419,70 & 419,70 & 333,00 & 333,00 \\
\hline & & & & & lanço total & 1674,44 & 124,19 \\
\hline
\end{tabular}

O Quadro 8 compara os resultados obtido com a análise dos balanços atuais com os balanços obtidos com o cenário apresentado.

\section{5) Discussão e validação dos resultados do estudo com os agentes do sector}

Ao longo da execução do presente estudo, forma consultadas um conjunto de entidades, as quais contribuíram para a melhoria e validação da metodologia e com informação diversa. Ao longo do processo foi realizado a 04 de abril de 
2019 um workshop, o qual contou com a presença de 22 entidades. Dos principais resultados concluiu- se que:

O modelo metodológico proposto é adequado e revela ter um potencial elevado para a análise dos fluxos de biomassa;

Existe a necessidade de melhorar a quantidade e qualidade da informação de suporte, bem como a sua atualidade, fundamental para que os resultados obtidos possam ser mais fidedignos;

A necessidade de reforçar o trabalho através da colaboração das diferentes entidades que produzem e/ou são detentores de informação relevante para o estudo.

\section{Conclusões}

No contexto das atuais políticas florestais e energéticas é importante encontrar soluções a curto/médio prazo que permitam a valorização da fração de biomassa florestal que atualmente não é utilizada quer pela via do desenvolvimento de novos bioprodutos, numa lógica do uso em cascata, quer pela via da mobilização dessa biomassa, que em grande parte é responsável pelos problemas dos fogos rurais. O aumento previsível da procura de biomassa florestal para estes fins requer o desenvolvimento de abordagens metodológicas mais robustas que permitam analisar as relações entre objetivos muitas vezes concorrentes entre si, que permitam a tomada de decisão de nível estratégico.

Este estudo teve como principal contribuição a definição de uma abordagem para a caracterização dos fluxos de abastecimento da BF em Portugal, que resultou da revisão da literatura e que se resume em:

1. Sistematização dos conceitos e definições relacionadas com a produção e o consumo da biomassa. As categorias de biomassa florestal são: (BFP) Biomassa florestal primária, (BFR) Biomassa florestal residual, (SI) Sobrantes industriais; (PC) Material lenhoso pós-consumo. As categorias de utilização da BF são: as indústrias de base florestal ditas tradicionais (pasta e papel, serrações e painéis), (BE) Bioenergia, (BC) Biocombustíveis e (BP) Bioprodutos.

2. Identificação das fontes de informação relevantes, bem como lacunas relacionadas com a falta de informação ou a qualidade da informação existente.

3. Utilização do diagrama de Sankey para representação visual dos fluxos e capacidades instaladas. Esta ferramenta permite a elaboração de cenários 
de evolução desses fluxos de abastecimento da biomassa florestal, por via de alterações na produção (i.e., volumes produzidos) e/ou no consumo (i.e., capacidades das unidades de processamento e consumos).

Outra importante contribuição foi a aplicação da abordagem proposta para uma macro análise dos balanços no abastecimento de BF em Portugal, que para 2016 se pode resumir: 1) na disponibilidade total de biomassa foi na ordem das 1674,83 mil toneladas, ou seja, num excedente de biomassa. Estes resultados sugerem que é possível aumentar a capacidade e/ou desenvolver novas biorrefinarias para obtenção de novos bioprodutos. No entanto, deverão ser analisados cuidadosamente quais as tipologias a utilizar e os impactos nas respetivas disponibilidades; 2) O cenário apresentado sugere a existência de situações que possam levar à rutura de stocks para algumas categorias de biomassa florestal, se considerarmos as atuais quantidades de biomassa produzida e as exigências de consumo devido ao aumento da sua procura, que requer repensar a sua utilização.

Uma vez que que se prevê um aumento de unidades de consumos de biomassa florestal, é necessário otimizar a utilização das diversas tipologias, de modo a conseguir dar resposta a essas necessidades sem colocar em risco, nem a sustentabilidade dos recursos, nem o abastecimento às unidades de consumo.

Ressalta-se que apesar dos balanços totais à escala nacional serem positivos, isto não quer dizer que o mesmo se verifique na escala regional. Podem verificar-se situações em que a produção está centralizada numa região, mas o consumo noutra, que não são detetáveis neste estudo à escala nacional, mas que são determinantes para o seu real aproveitamento. A este propósito, é muito importante referir que a perspetiva de alguns dos agentes do setor, existe um déficit na oferta de biomassa florestal em diversas regiões. Pelo que são necessários estudos complementares que têm em conta a geografia da produção e dos consumos.

As principais limitações do estudo, que poderão condicionar estes resultados, são:

- A necessidade de informação de qualidade e em quantidade que permita uma análise das várias componentes que compõem os fluxos de abastecimento de biomassa florestal;

- A falta de um enquadramento estruturado que tenha em conta um conjunto de indicadores comuns que permitam avaliar a sustentabilidade de utilização dos recursos florestais para as suas várias utilizações; 
- A deficiência ao nível de modelos integrados de análise que permitam avaliar os fluxos de abastecimento no seu conjunto.

A partir da análise da literatura e de casos de sucesso nos outros países, identificaram-se áreas potencialmente promissoras para o desenvolvimento de novas cadeias de abastecimento de biomassa florestal em Portugal, nomeadamente:

- A introdução de redes de calor para aquecimento doméstico edifícios e infraestruturas públicas, assente em redes de transformação regional e local;

- Outras redes de calor para agroindústria, por exemplo para o aquecimento de estufas associadas à produção de culturas protegidas, aviários, entre outras aplicações;

- O recurso a culturas energéticas de origem florestal, com o objetivo de não criar pressão sobre os atuais recursos florestais, sendo necessário estudos e experiências que suportem uma tomada de posição sobre esta questão.

Realçamos que as conclusões aqui explanadas deverão ser interpretadas com as devidas cautelas, tendo em conta as questões já referidas, nomeadamente quanto à escala de análise e dos problemas associados com a informação.

No entanto, cremos estar perante uma metodologia com elevado potencial para aplicação em análises de âmbito estratégico a nível nacional, propondo que a mesma seja adotada pelas entidades publicas responsáveis pela definição de políticas ao nível florestal e da bioeconomia.

Como propostas de desenvolvimento futuro, podemos referir a necessidade de aplicação da metodologia proposta a escalas regionais que permitam fornecer informação e apoio à decisão a uma escala mais operacional, estudar modelos integrados de aproveitamento das diferentes categorias de biomassa no sentido de dar resposta às diferentes possibilidades de utilização e estudar fluxos alternativos aprofundando outros cenários possíveis. A introdução e outras fontes de biomassa na análise dos fluxos de abastecimento para a produção de bioenergia e bioprodutos, nomeadamente a nível regional, será igualmente uma linha de investigação promissora.

\section{Agradecimentos}

O trabalho que deu origem a este artigo foi desenvolvido no âmbito do projeto 0095_BIOTECFOR_1_P, cofinanciado pelo Fundo Europeu de 
Desenvolvimento Regional (FEDER) através do Programa Interreg V-A EspanhaPortugal (POCTEP) 2014-2020. Contém ainda resultados de investigação produzidos no âmbito dos seguintes projetos de investigação: Easyflow ERDF European Regional Development Fund through the Operational, Programme for Competitiveness and Internationalisation - COMPETE 2020 Programme and by National Funds through the Portuguese, funding agency, FCT - Fundação para a Ciência e a Tecnologia within project POCI-01-0145-FEDER-016733 (Easyflow). GOTECFOR - Tecnologia para a mobilização e aproveitamento de Biomassa Florestal na agroindústria, Grupo Operacional, 2017-2020. Agradecemos a disponibilidade e apoio das seguintes pessoas: Graça Torres (DGEG), Graça Louro e Cristina Santos (ICNF), João Ferreira (ANPEB), Pedro Teixeira (Centro Pinus), Alexandre Gaspar (The Navigator Company - Raiz), Teresa Almeida e Sónia Figo (CBE), José Lousada (UTAD), Leónia Nunes (CEABN). Agradecemos ainda, em particular, os contributos do Luís Leal e Luís Ferreira (Altri).

\section{Bibliografia}

ARANO, I. M. de et al., 2018. A forest-based circular bioeconomy for southern Europe: visions, opportunities and challenges. Reflections on the bioeconomy. Available at: https://www.efi.int/sites/default/files/files/publication-bank/2018/Reflections.

BIO-BASED INDUSTRY CONSORTIUM, 2013. Strategic Innovation and Research Agenda (SIRA): Bio-based and Renewable Industries for Development and Growth in Europe, (March), p. 49. Available at: http://biconsortium.eu/sites/biconsortium.eu/ files/downloads/BIC_BBI_SIRA_web.pdf.

CAMIA, A. et al., 2018 Biomass production, supply, uses and flows in the European Union. First results from an integrated assessment, ISBN978-92-79-77237-5. https:// doi.10.2760/539520, pp. 1-126. doi: 10.2760/181536.

CELPA, 2017. Boletim estatístico. Indústria Papeleira Portuguesa. doi: 10.1360/zd-2013-43-61064.

CENTRO PINUS, 2017. A FILEIRA DO PINHO EM 2016 Indicadores da Fileira do Pinho.

COMISSÃO EUROPEIA, 2012. Inovação para um Crescimento Sustentável: Bioeconomia para a Europa - COM(2012) 60 final.

COMISSÃO EUROPEIA, 2015. Fechar o ciclo - plano de ação da UE para a economia circular . $\operatorname{COM}(2015) 614$ final.

CUBA, N., 2015. Research note: Sankey diagrams for visualizing land cover dynamics, Landscape and Urban Planning. Elsevier B.V. 139: 163-167. doi: 10.1016/j.landurbplan. 2015.03.010. 
36 Cunha, J. e Marques, A.

DIÁRIO DA REPÚBLICA, 2015. Resolução do Conselho de Ministros n.o 6-B/2015 Estratégia Nacional para as Florestas (ENF), Diário da República, 1.a série - N.o 24.

DIÁRIO DA REPÚBLICA, 2017a. Plano de Ação para a Economia Circular em Portugal, Diário da República, 1. a série - N.o 236(54): 54-73. doi: 10.1017/CBO9781107415324.004.

DIÁRIO DA REPÚBLICA, 2017b. Resolução do Conselho de Minstros n.o 163/2017 - Plano Nacional para a Promoção das Biorrefinarias. Diário da República, 1a série, n.o 210.

FAO, 2006. Introducing the Bioenergy Platform International (IBEP).

FERNANDES, P.M., 2009. Original article Combining forest structure data and fuel modelling to classify fire hazard in Portugal, 66, pp. 1-9.

FERREIRA, S. et al., 2017. Biomass resources in Portugal: Current status and prospect, Renewable and Sustainable Energy Reviews 78:1221-1235. doi: 10.1016/j.rser.2017.03.140.

HETEMÄKI, L., 2014. Future of European Forest-Based Sector. doi: 10.13140/2.1.3687.3929.

ICNF, 2016. Fileiras florestais. SETOR FLORESTAL | 2016, 905, pp.. Available at: www.icnf.pt/portal/florestas/fileiras/resource/docs/sintese-economica.

INE, 2016. Estatísticas do Ambiente 2016.

INE, 2018. Estatísticas Agrícolas - 2017. doi: 0079-4139.

IRENA, 2019. Bioenergy from boreal forests. Swedish approach to sustainable wood use. International Renewable Agency, Abu Dhabi.

KARJALAINEN, T. et al. (2004) Estimation of energy wood potential in Europe, Working Papers of the Finnish Forest Research Institute. Available at: http://www.metla.fi/julkaisut/ workingpapers/2004/mwp006.htmwww.metla.fi.

LENGLET, J., COURTONNE, J., CAURLA, S., 2017. Material flow analysis of the forest-wood supply chain: A consequential approach for log export policies in France, Journal of Cleaner Production. Elsevier Ltd, 165: 1296-1305. doi: 10.1016/j.jclepro.2017.07.177.

LOURO, G. et al., 2013. As Fileiras Baseadas na Floresta: Análise Sectorial. Silva Lusitana. Estação Florestal Nacional. Available at: http://www.scielo.mec.pt/scielo.php?

script=sci_arttext\&pid=S0870-63522013000100001.

PATRÍCIO, M. do S., et al., 2013. Produção potencial de biomassa em culturas energéticas lenhosas no Norte de Portugal. Atas CD 70Congresso Florestal Nacional: Artigos / Comunicações. João Bento, José Lousada, Maria do Sameiro Patrício, pp. 362-368. Available at: https://bibliotecadigital.ipb.pt/handle/10198/9850.

SCHMIDT, M., 2008. The Sankey Diagram in Energy and Material Flow Management Part I: History, 12(1). doi: 10.1111/j.1530-9290.2008.00004.x.

SHANNON, S.E., 2005. Three Approaches to Qualitative Content Analysis, 15(9): 1277-1288. doi: $10.1177 / 1049732305276687$.

SILLANPÄÄ, M., NCIBI, C., 2017. A Sustainable Bioeconomy. Cham: Springer International Publishing. doi: 10.1007/978-3-319-55637-6. 
SOUNDARARAJAN, K., HO, H.K., SU, B., 2014. Sankey diagram framework for energy and exergy flows, Applied Energy. Elsevier Ltd, 136: 1035-1042. doi: 10.1016/j.apenergy.2014.08.070.

VERKERK, P.J., MARTINEZ DE ARANO, I.. PALAHÍ, M., 2018. The bio-economy as an opportunity to tackle wildfires in Mediterranean forest ecosystems, Forest Policy and Economics. Elsevier, 86 :1-3. doi: 10.1016/j.forpol.2017.10.016. 